\title{
Thermal stability of gold-PS nanocomposites thin films
}

\author{
UMANANDA M BHATTA, DEEPA KHUSHALANI ${ }^{\dagger}$ and P V SATYAM* \\ Institute of Physics, Sachivalaya Marg, Bhubaneswar 751 005, India \\ ${ }^{\dagger}$ Materials Chemistry Group, Department of Chemical Sciences, TIFR, Mumbai 400 005, India
}

MS received 26 October 2009; revised 5 February 2010

\begin{abstract}
Low-temperature transmission electron microscopy (TEM) studies were performed on polystyrene (PS, $M_{\mathrm{w}}=234 \mathrm{~K}$ ) - Au nanoparticle composite thin films that were annealed up to $350^{\circ} \mathrm{C}$ under reduced pressure conditions. The composite thin films were prepared by wet chemical approach and the samples were then subsequently spin-coated on a carbon-coated copper grid for TEM measurements. TEM measurements were performed at liquid nitrogen temperatures to reduce the electron-beam-induced radiation damage. The results showed a marginal increase in Au nanoparticle diameter $(2.3 \mathrm{~nm}-3.6 \mathrm{~nm})$ and more importantly, an improved thermal stability of the polystyrene (PS) composite film much above its glass transition temperature.
\end{abstract}

Keywords. Thermal stability; polymer nanocomposites; low temperature electron microscopy.

\section{Introduction}

Thin polymer films play a very important role in modern day technology: polymer coatings help to preserve, isolate or decorate underlying materials. As such, stability of these polymer coatings under a variety of conditions is mandatory. For example, such coatings may have to sustain a large variation in temperature, be compatible with a substrate on which it is being coated and be chemically inert to the surrounding atmosphere. Over the last decade, there have been several reports that have analyzed thermal and mechanical stability of a variety of polymer thin films (Reiter 1992; Reiter 1994; Xie et al 1998; Jacobs et al 1998). Among many methods in improving thermal stability, the incorporation of inorganic particles into a polymer is one such method. A representative example of such alteration was recently shown by Huber and coworkers, where it was detailed that when carbon black was added to a rubber melt, there was an improvement in the strength and durability of the composite (Huber et al 1996). Over the years, further refinement to this concept has been achieved by addition of specific nanoparticles (NP) to a polymer. Compared to bulk inorganic structures, NPs have the advantage that they have a high surface to volume ratio. As such, they have been proving to be more effective at modifying properties, specifically such as the electronic and optical aspects. Correspondingly the polymer matrix also plays an important role in stabilizing the nanoparticles. Stabilization of nano-

\footnotetext{
*Author for correspondence

(satyam@iopb.res.in, pvsatyam22@gmail.com)
}

particles by high-molecular weight compounds is a major branch of modern polymer colloidal science. Hence, the natural and synthetic polymers are largely used as stabilizers during storage and transportation. Nanoparticles are very sensitive to impurities, tend to coalesce under high concentrations and/or temperatures and also are known to alter their surface structure upon exposure to light. In general, these effects are found to be irreversible in nature. In polymer nanocomposites, the interface between the polymer matrix and the nanoparticles plays an important role and as a result, there have been a lot of studies on both these fronts - improving properties of polymer by the incorporation of nanoparticles and vice versa (Lee and Park 2000; Liu et al 2003; Wilson et al 2004; Boldyryeva et al 2005; Macanas et al 2006; Muraviev et al 2007). As mentioned earlier this includes enhancing the optical, magnetic, mechanical and electrical properties of the system. This can be utilized in various technological applications in various fields including medical field (Sharma et al 2009). As electron microscopy of polymers involves e-beam induced radiation damage, by using liquid nitrogen $\left(\mathrm{LN}_{2}\right)$ in the specimen stage e-beam induced temperature effects can be reduced. This helps to study the thermal stability-microstructure relation in polymer nanocomposites (PNC) films using TEM.

Metal-polymer nanocomposites can be obtained by two different approaches, namely, in situ and ex situ. Metal nanoparticles are generated inside the polymer matrix by the chemical reduction of metallic salts dissolved in the polymer solution in in situ method; whereas in the case of ex situ method, which we have followed in the present work, nanoparticles are produced by chemical methods 
and are then dispersed into a polymer matrix. Here, it is important that the chemical route chosen for the preparation of metal nanoparticles allows having a passivated surface on the nanoparticles. $n$-alkanethiol molecules (i.e. $\mathrm{C}_{n} \mathrm{H}_{2 n+1} \mathrm{SH}$ ) can be a good surfactant, as it helps not only to avoid agglomeration and surface oxidation/contamination but also in the proper mixing with the hydrophobic polymer matrix. In other methods, ion implantation has also been used successfully to incorporate nanoparticles into a polymer matrix (Boldyryeva et al 2005).

Structural characterization of such soft systems is a very critical step. It is vital when performing any measurements that the probe being used for characterization itself should not damage these soft systems. Apart from several optical techniques, X-ray and neutron (reflectivity, scattering, etc) have also been used to study diffusion of particles inside polymer matrix (Lin et al 1999; Grull et al 2002; Shin et al 2003; Narayanan et al 2005; Narayanan et al 2007). In this paper, we report the thermal stability of PS films that have been embedded with dodecane thiol (DDT) capped Au particles and annealed at various temperatures in a separate annealing furnace at reduced pressure conditions.

\section{Experimental}

DDT capped gold nanoparticles were similar to the preparation given by Choo et al (2003). A mixture of $0.12 \mathrm{~g}(0.6 \mathrm{mM})$ of 1 -dodecanethiol and $0.12 \mathrm{~g}(0.6 \mathrm{mM})$ of mercapto propanol was dissolved in $20 \mathrm{ml}$ of tetrahydro furan (THF). This was added to a solution of $0.24 \mathrm{~g}$ $(0.6 \mathrm{mM})$ of $\mathrm{HAuCl}_{4} \cdot 3 \mathrm{H}_{2} \mathrm{O}$ in $50 \mathrm{ml}$ of THF with vigorous stirring for $10 \mathrm{~min}$. Then $0.23 \mathrm{~g}(6.0 \mathrm{mM})$ of $\mathrm{NaBH}_{4}$ in $10 \mathrm{ml}$ of millipore water was added over a period of $5 \mathrm{~s}$. The color of the solution changed immediately from pale yellow to black upon the addition. The reaction mixture was stirred for $2 \mathrm{~h}$ and the solvent was removed using a rotary evaporator. The black precipitate was suspended in $100 \mathrm{ml}$ of acetonitrile, briefly sonicated to promote dissolution of impurities, and filtered and washed with millipore water, acetonitrile and acetone. $1 \mathrm{ml}$ of this colloid was added to a solution of $50 \mathrm{mg}$ polystyrene (PS $234 \mathrm{~K}$ ) in $10 \mathrm{ml}$ toluene and stirred $\mathrm{v}$ igorously to get an Au-PS PNC.

Specimen for TEM measurements was prepared by spin coating the prepared polymer nanocomposites on a carbon coated grid. Coating was done at $2000 \mathrm{rpm}$ for $40 \mathrm{~s}$ to ensure thin, electron transparent films. The annealing set up had a capacity of heating the sample from RT to $1400^{\circ} \mathrm{C}$. Annealing was done under low vacuum conditions $\left(\approx 10^{-2} \mathrm{mbar}\right)$. The sample was heated up to desired temperatures $\left(100^{\circ} \mathrm{C}, 200^{\circ} \mathrm{C}, 300^{\circ} \mathrm{C}\right.$ and $350^{\circ} \mathrm{C}$ ) at a rate of ca. $7^{\circ} \mathrm{C} \mathrm{min}^{-1}$ and kept at each temperature for $4 \mathrm{~h}$. TEM observations were carried out in a $200 \mathrm{keV}$ (JEOL, 2010). In order to prevent sample degra- dation due to beam damage, a double tilt liquid nitrogen cooled holder (Model 636, Gatan) was used. Specimen mount is made up of beryllium which was cooled to $-177^{\circ} \mathrm{C}$ with liquid nitrogen and temperature was maintained during the entirety of each TEM measurement.

\section{Results and discussions}

Figure 1 shows a TEM micrograph of as-prepared AuPNC. Hydrophobic capping of the Au particles ensures a good dispersion in the polymer matrix without much aggregation. This system was stable under high energy electron beam when we carried out measurements using a $\mathrm{LN}_{2}$ cold stage holder. About 200 particles were used to study the sizes and the corresponding histogram (figure 1b) was fitted with a Gaussian distribution. The average size of the particles was measured to be about $2 \cdot 3 \pm 0 \cdot 1 \mathrm{~nm}$. This specimen was ex situ annealed in a low vacuum furnace for $4 \mathrm{~h}$ each at various temperatures sequentially and TEM measurements taken after each annealing.

Average size of these particles after annealing at $100^{\circ} \mathrm{C}$ was $\sim 2.5 \pm 0 \cdot 1 \mathrm{~nm}$ (figure 2a). Distribution was narrower (corresponding histograms are given on right hand side for each temperature) as compared to the RT case but there are still a few particles with larger size which form the tail of the distribution. Figure $2 b$ shows the micrograph taken after the sample was annealed at $200^{\circ} \mathrm{C}$. Some of the particles seem to be coagulated and as a result we see an even distribution with not many particles towards the tail of the distribution. At this temperature, the mean size was $\sim 2 \cdot 8 \pm 0 \cdot 1 \mathrm{~nm}$. The most interesting aspect noticed was that even after annealing much above $T_{\mathrm{g}}$, the polymer film was stable. It should be noted that glass transition temperature of PS is about $95^{\circ} \mathrm{C}$. Mobility of gold particles through the polymer network and mobility of polymer molecules around gold particles depends on the bonding between a gold particle and the polymer molecules in direct contact with the particle. Around $T_{\mathrm{g}}$, at the surface of the glassy film a liquid like layer exists which increases in volume as the $T_{\mathrm{g}}$ is approached. So, above this temperature secondary, non-covalent bonds become weak, polymer becomes soft and the particles embedded inside will become more mobile leading to coalescence of these particles with increasing temperature. The gold diffusion is dominated by the bridging interactions between the particles. The transient network formed by the bridges slows down the particle diffusion drastically, while the molecules not in contact with the particles will move more freely. With increasing temperature above glass transition temperature bond strength between a gold particle and polymer molecules reduces. As a result the nanoparticles start to diffuse freely through the polymer network. More and more nanoparticles come in contact with each other, and eventually coagulation of these particles occurs. Similar conclusions 

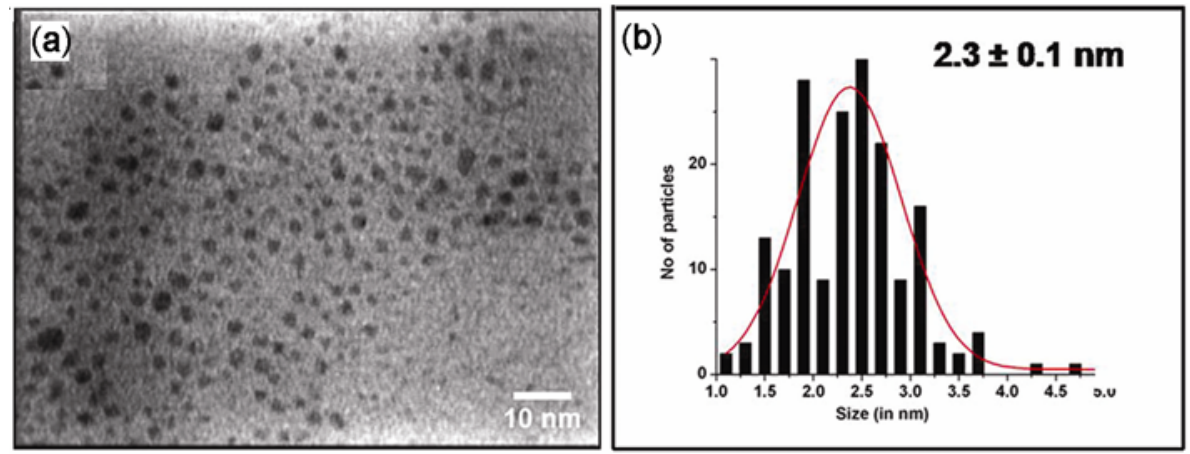

Figure 1. (a) Bright field TEM micrograph showing Au nanoparticles embedded in PS matrix at RT. (b) Corresponding histogram showing an average size of $2.3 \mathrm{~nm}$. The solid line represents the fitted curve with Gaussian distribution.
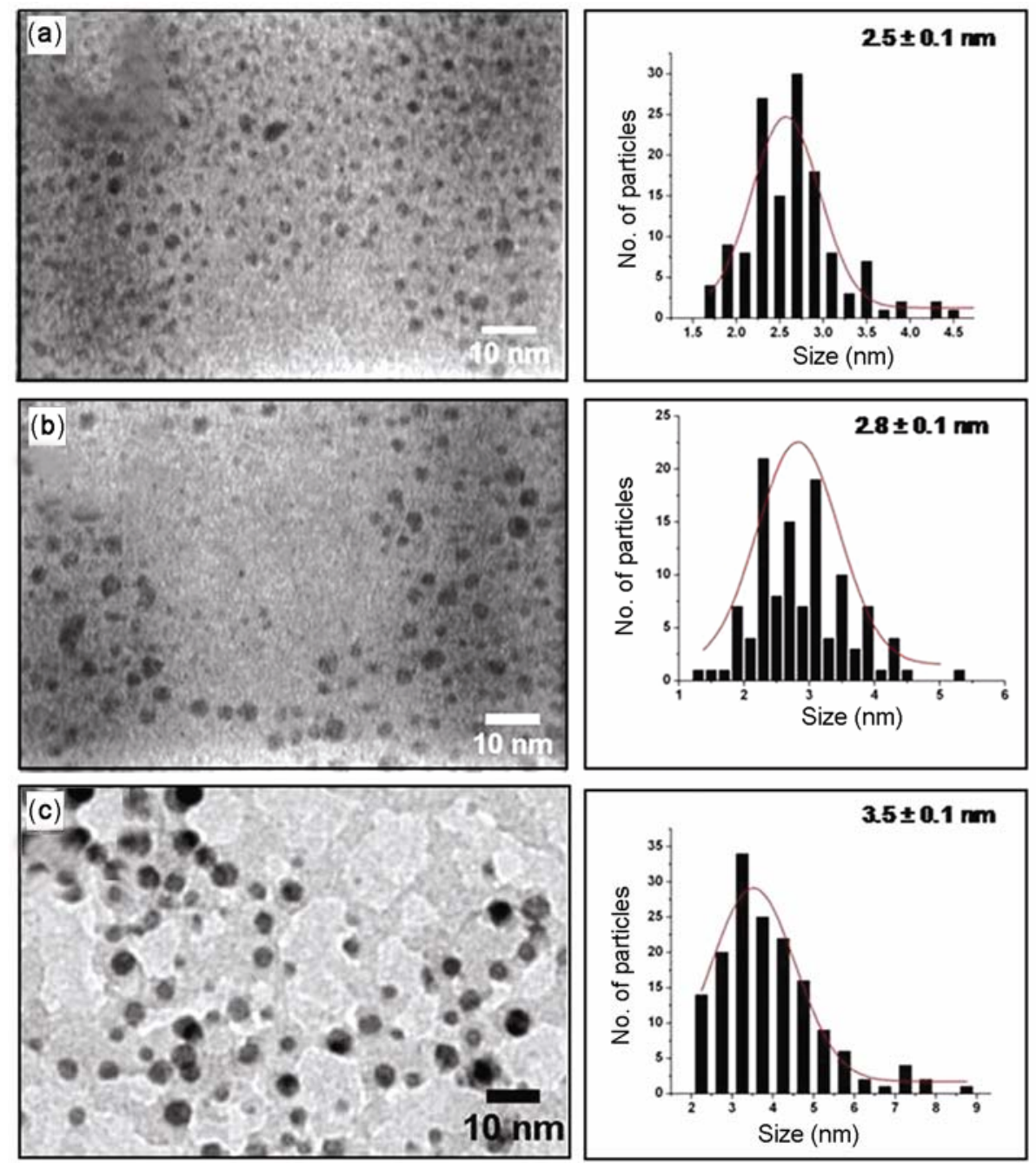

Figure 2. Bright field TEM micrographs showing the process of coagulation of $\mathrm{Au}$ nanoparticles after annealing the specimen at (a) $100^{\circ} \mathrm{C}$, (b) $200^{\circ} \mathrm{C}$ and (c) $300^{\circ} \mathrm{C}$. Corresponding histograms and their average sizes are given on the right hand side. The solid line represents the fitted curve with Gaussian distribution.

have been corroborated by several other groups also in case of such metal-polymer systems (Kunz et al 1993; Keddie et al 1994; Cole et al 1997; Faupel et al 1998).
After annealing at $300^{\circ} \mathrm{C}$, the mean size of the particles was $\sim 3.5 \pm 0 \cdot 1 \mathrm{~nm}$. The maximum size of the nanoparticles was measured up to as large as $9.0 \mathrm{~nm}$ (figure 2c). 

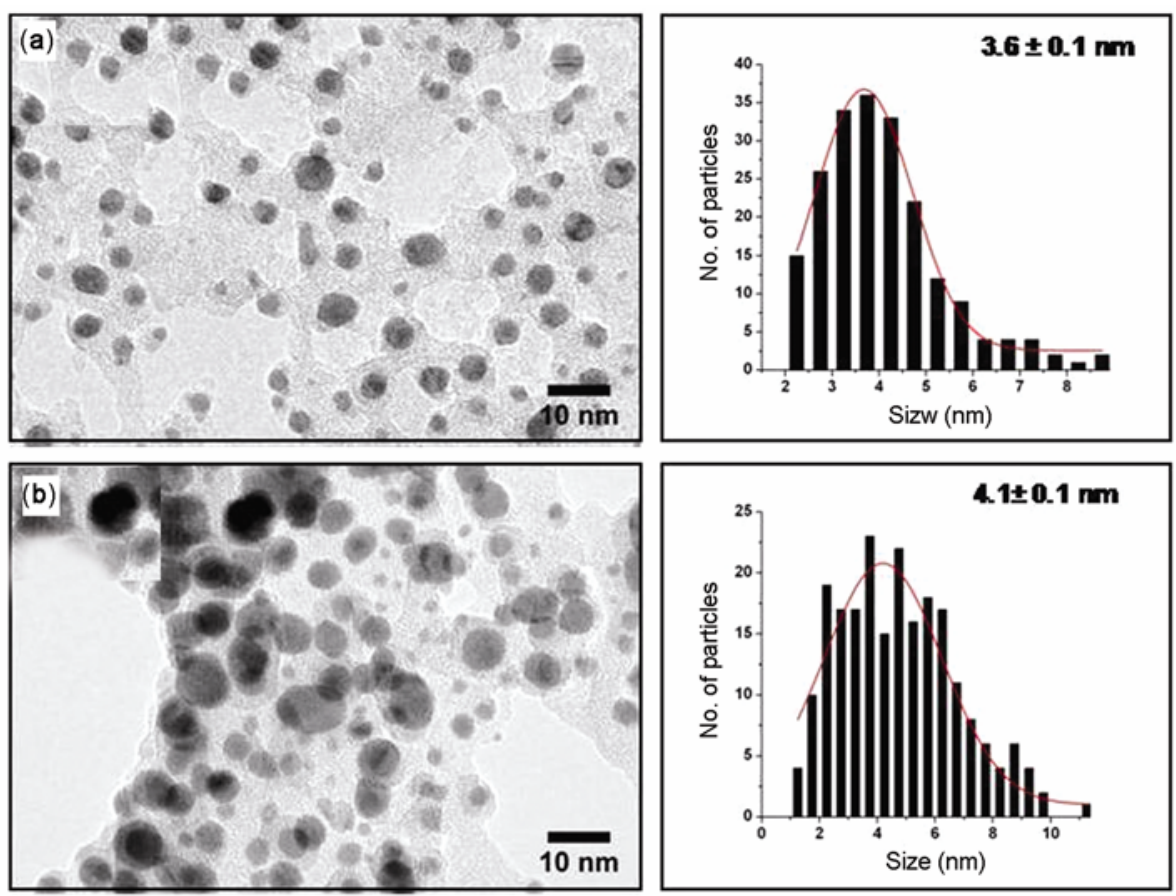

Figure 3. Bright field TEM micrographs showing the distribution of Au nanoparticles (a) far away from the ruptured edges and (b) near the ruptured edges, after the film was annealed at $350^{\circ} \mathrm{C}$. Average size of the $\mathrm{Au}$ nanoparticles near these edges was $4 \cdot 1 \mathrm{~nm}$. The solid line represents the fitted curve with Gaussian distribution.

Strunskus et al (1999) have studied the growth and the distribution of $\mathrm{Cu}$ clusters in polyimide film annealed at different temperatures. No clusters were visible after annealing the thin film below $100^{\circ} \mathrm{C}$. The authors reasoned that even though large amount of metal existed inside the film because of small size those clusters did not generate enough TEM contrast. The mean cluster diameter increased from $6 \mathrm{~nm}$ at $100^{\circ} \mathrm{C}$ to $16 \mathrm{~nm}$ at $250^{\circ} \mathrm{C}$. No further cluster growth was observed after annealing the film at temperatures above $250^{\circ} \mathrm{C}$ (Strunskus et al 1999). In our case also coagulation process slows down considerably after $300^{\circ} \mathrm{C}$ and we see a very small increase in size at $350^{\circ} \mathrm{C}(3 \cdot 6 \pm 0 \cdot 1 \mathrm{~nm})$ (figure $\left.3 \mathrm{a}\right)$.

First signs of film damage was seen at $300^{\circ} \mathrm{C}$ (well above its glass transition temperature) in the form of small patches, due to dewetting of the polymer film with the carbon support (figure 2c). Earlier studies have reported that PS thin films (without any embedded nanoparticles) started to develop number of large holes (as a result of rupture) when annealed just above its glass transition temperature (Reiter 1992; Jacobs et al 1998). Lee et al (2006) have reported the effect of incorporation of Pd nanoparticles on the thermal stability of atactic polystyrene (aPS) by using thermo-gravimetric analysis (TGA). The authors observed that incorporation of a small amount of Pd nanoparticles into aPS film remarkably improves the thermal stability because it increases the temperature at which the degradation begins by about $50^{\circ} \mathrm{C}$. It has also been reported that thermal decomposi- tion of PMMA can be retarded by the incorporation of Pd nanoparticles (Aymonier et al 2003).

After the specimen was annealed at $350^{\circ} \mathrm{C}$, large scale rupturing of the thin film was observed at several places. In such places the gold nanoparticles seemed to aggregate more towards the edges of the ruptured film (figure $3 b$ ) and average size of the nanoparticles here was larger $(4 \cdot 1 \pm 0 \cdot 1 \mathrm{~nm})$ than what was observed at places away from these edges.

Figure 4 shows high resolution TEM image of gold particle in a polymer matrix with a $d$ spacing of $0 \cdot 235 \pm 0.005 \mathrm{~nm}$ corresponding to Au (111) plane for $350^{\circ} \mathrm{C}$ annealed system. The image has been filtered (digital micrograph) for better clarity. The FFT of the original image was taken and the resulting diffractogram was filtered using masking technique. Inverse FFT of such a diffractogram gives a clear high resolution image of gold nanoparticles.

\section{Conclusions}

Au-PS nanocomposites were prepared by incorporating chemically prepared gold nanoparticles into a PS-toluene solution. This was spin cast on a c-coated copper grid for TEM measurements. The specimen was subjected to various temperatures (up to $350^{\circ} \mathrm{C}$ ) and TEM measurements were taken using a cold stage holder after each annealing. It was observed that $\mathrm{Au}$ particles improve the 

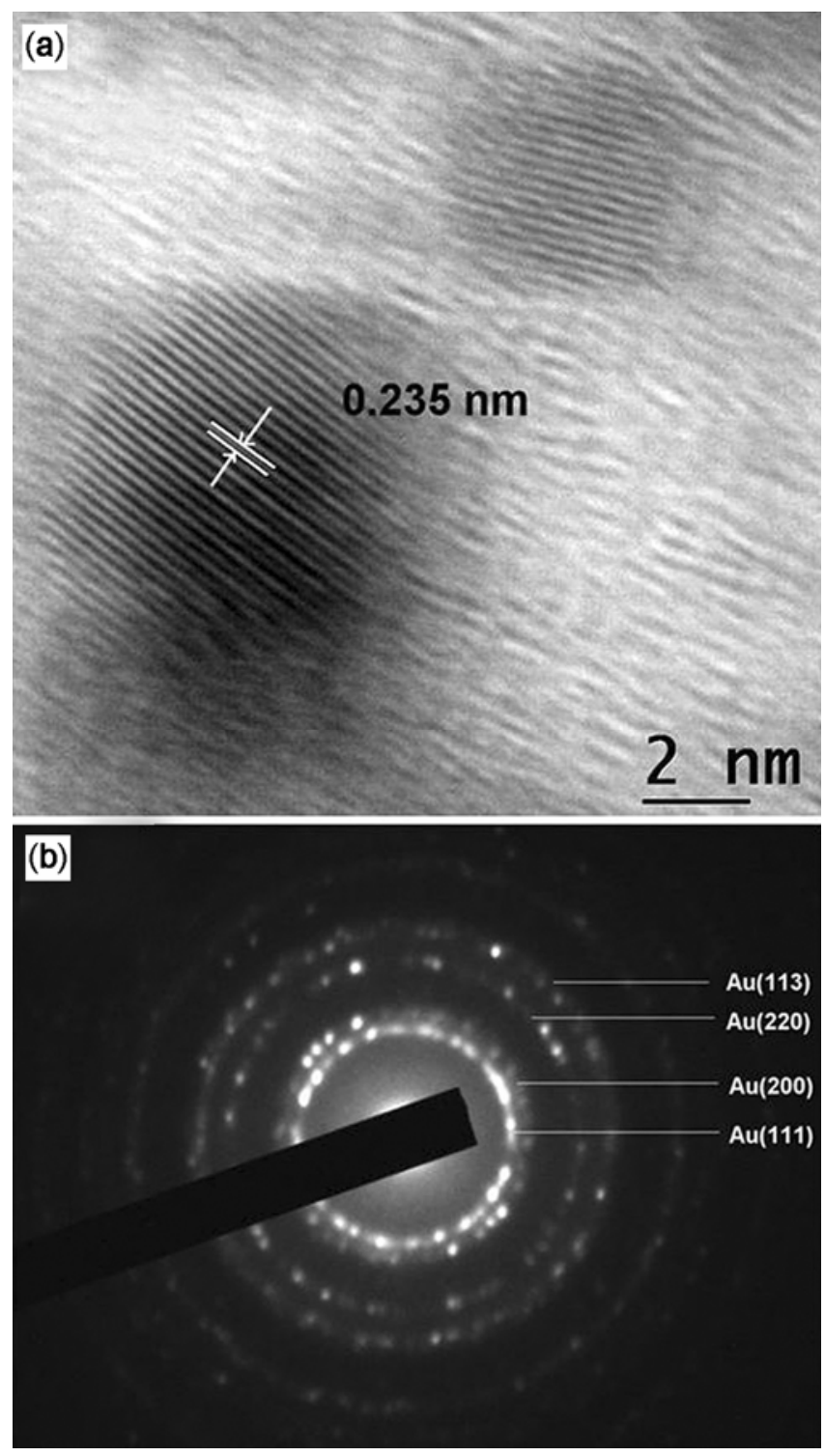

Figure 4. (a) TEM micrograph showing high resolution image of two typical Au nanoparticles embedded in PS matrix after the sample was annealed at $350^{\circ} \mathrm{C}$. The lattice spacing was measured to be $0.235 \pm 0.005 \mathrm{~nm}$, corresponds to $\mathrm{Au}(111)$ plane. (b) Selected area diffraction showing the presence of polycrystalline gold.

thermal stability of the polymer thin film well beyond its glass transition temperature. A slight increase in the average size of particles from $2.3 \mathrm{~nm}$ to $3.6 \mathrm{~nm}$ was observed.

\section{Acknowledgement}

The financial support from the department of atomic energy, Government of India, (project no: 11-R\&D-IOP5.09-0100) is acknowledged.

\section{References}

Aymonier C, Bortzmeyer D, Thomann R and Mülhaupt R 2003 Chem. Mater. 154874

Boldyryeva H, Umeda N, Plaksin, Takeda Y and Kishimoto N 2005 Surf. Coatings Technol. 196373

Choo H, Cutler E and Shon Y S 2003 Langmuir 198555

Cole D H, Shull K R, Rehn L E and Baldo P 1997 Phys. Rev. Lett. 785006

Faupel F, Willecke R and Thran A 1998 Mater. Sci. Engn. Reports A Rev. R22 1

Grüll H, Esker A R, Satija S K and Han C C 2002 Europhys. Lett. 57533

Huber G, Vilgis T A and Heinrich G 1996 J Phys: Condens. Mat. 8 L409

Jacobs K, Herminghaus S and Mecke K R 1998 Langmuir 14965

Keddie J L, Jones R A L and Cory R A 1994 Europhys. Lett. 2759

Kunz M S, Shull K R and Kellock A J 1993 J. Colloid Int. Sci. 156240

Lee T W and Park O O 2000 Adv. Mater. 12801

Lee J Y, Liao Y, Nagahata R and Horiuchi S 2006 Polymer 47 7970

Lin B, Morkved T L, Meron M, Huang Z, Viccaro P J, Jaeger H M, Williams S M and Schlossman M L 1999 J. Appl. Phys. 853180

Liu F K, Hsieh S Y, Ko F H, Chu T C and Dai B T 2003 Jpn. J. Appl. Phys. 424147

Macanás J, Farre M, Muñoz M, Alegret S and Muraviev D N 2006 Phys. Status Solidi 2031194

Muraviev D N, Macanás J, Esplandiu M J, Farre M, Muñoz M and Alegret S 2007 Phys. Status Solidi 2041686

Narayanan S, Lee D R, Guico R S, Sinha S K and Wang J 2005 Phys. Rev. Lett. 94145504

Narayanan S, Lee D R, Hagman A, Li X and Wang J 2007 Phys. Rev. Lett. 98185506

Reiter G 1992 Phys. Rev. Lett. 6875

Reiter G 1994 Macromolecules 273046

Sharma V K, Yngard R A and Lin Y 2009 Adv. Colloid \& Interface Sci. 14583

Shin K, Wang H, Satija S K, Han C C, Josell D and Bonevich J E 2003 J. Appl. Phys. 942115

Strunskus T, Behnke K and Zaporojtchenko V 1999 Interf. Controlled Mater., EUROMAT 9160

Xie R, Karim A, Douglas J F, Han C C and Weiss R A 1998 Phys. Rev. Lett. 811251

Wilson J L, Poddar P, Frey N A, Srikantha H, Mohomed K, Harmon J P, Kotha S and Wachsmuth J 2004 J. Appl. Phys. 951439 